\title{
Interdisciplinaridade, arte e cultura popular na educação básica segundo o discurso dos documentos legais vigentes ${ }^{1}$
}

\author{
Leonardo Marcelino* \\ Sueli Teresinha de Abreu Bernardes**
}

\begin{abstract}
Resumo
O objetivo deste artigo é analisar as menções à interdisciplinaridade, à arte e à cultura popular no discurso da legislação vigente nos aspectos em que se refere à educação básica. O corpus desta pesquisa abrange a Constituição da República Federativa do Brasil, a Lei de Diretrizes e Bases da Educação Nacional, o Plano Nacional de Educação e as Diretrizes Curriculares Nacionais Gerais para a Educação Básica vigentes. A análise documental proposta fundamentou-se em conceitos de Ivani Fazenda sobre interdisciplinaridade, de Ana Mae Barbosa sobre Arte-Educação, de Carlos Brandão sobre cultura popular e Luís Dourado sobre políticas educacionais. Os resultados expressam a preocupação com o acesso aos bens culturais e artísticos e às relações entre teoria e prática como dimensão interdisciplinar a ser alcançada. De modo específico nas Diretrizes menciona-se o ensino da arte em suas diferentes linguagens e propõe-se o ensino interdisciplinar por meio de projetos temáticos.

Palavras-chave: Interdisciplinaridade; Arte; Cultura popular; Legislação; Educação básica.
\end{abstract}

\section{Interdisciplinarity, art and popular culture in basic education according to the discourse of the current legal documents}

\begin{abstract}
This paper aims to analyze mentions of interdisciplinarity, arts and popular culture in the basic education aspects in its current legislation discourse. The corpus of this research is composed of the current Constitution of Federative Republic of Brazil, National Educational Bases and Guidelines Law, National Education Plan and General National Curriculum Directives for Basic Education. The documentary analysis is based on Ivani Fazenda's interdisciplinary concepts, on Ana Mae Barbosa's Art-Education, on Carlos Brandão's popular culture and Luís Dourado's education policy. In general, the findings highlight the concern about the access to artistic and cultural assets as well as the link between theory and practice as interdisciplinary dimension to be achieved. Specifically, the Guidelines mention the teaching of art in its different languages and focus on the interdisciplinary teaching using thematic projects.

Keywords: Interdisciplinarity; Art; Popular Culture; Legislation; Basic Education.
\end{abstract}

\section{Introdução}

Neste artigo objetiva-se analisar as menções à interdisciplinaridade, à arte e à cultura popular no discurso da legislação vigente nos aspectos em que se refere à educação básica. O corpus é constituído pela Constituição Federal promulgada em 1988, a Lei de Diretrizes e Bases da Educação Nacional (1996), o Plano Nacional de Educação (2014) ou Lei 13005/14 e as Diretrizes Curriculares Nacionais Gerais para a Educação Básica (2010).

Sobre os conceitos escolhidos, fez-se inicialmente, algumas considerações. A interdisciplinaridade como objeto de pesquisa é ressaltada, sobretudo, na década de 1960 quando Georges Gusdorf apresentou à UNESCO um projeto de pesquisa interdisciplinar para as ciências humanas. Segundo Fazenda (2001, p. 18), o intuito de Gusdorf era o "rompimento a uma educação por

** Endereço eletrônico: leonardomarcelino.group@gmail.com

*** Endereço eletrônico: abreubernardes@terra.com.br migalhas". Para essa autora, ainda não há uma definição exata do que é interdisciplinaridade. Contudo, esse conceito pode ser identificado por meio de algumas características, como a superação de várias dicotomias - teoria/prática, ciência/arte, objetividade/subjetividade, luta/resistência, solidão/desejo de encontro, além de outras como alteridade, gosto pela pesquisa, espera, compromisso do professor para com seus alunos e o diálogo.

A interdisciplinaridade é mais uma categoria de ação do que conhecimento (FAZENDA, 2001). É necessária a presença de pelo menos duas disciplinas e um ponto tangencial no qual exista diálogo entre elas. Veremos, nas análises da legislação educacional, o modo pelo qual o governo a estabeleceu nas políticas educacionais.

$\mathrm{O}$ surgimento do cientificismo em meados do século XIX trouxe competividade entre as ciências, nas quais o conhecimento científico era tido 
como verdade indestrutível, e foi uma das possíveis causas da fragmentação da ciência, descontextualizando o ensino e fazendo-o perder a noção de unidade e totalidade. Fazenda (2001, p.19, grifo da autora) revela que "à medida que nos distanciássemos de um conhecimento em totalidade, estaríamos decretando a falência do humano, a agonia de nossa civilização".

Embora não se tenha chegado a uma única teoria, Fazenda (2008) define algumas de suas características como a interação, a reciprocidade, a humildade, a espera, o desapego, a unidade, a totalidade, a afetividade e a ousadia. O conhecimento já instituído não é substituído pelo novo, pois impera o respeito, o diálogo com outras fontes de saber.
Lenoir
(2008)
diferencia

interdisciplinaridade escolar e científica. A primeira caracteriza-se pela:

\begin{abstract}
difusão do conhecimento [...] e a formação de atores colocando-se em prática as condições mais apropriadas para suscitar e sustentar desenvolvimento dos processos e a apropriação dos conhecimentos como produtos cognitivos com os alunos; isso requer uma organização dos escolares sobre os planos curriculares, didáticos e pedagógicos; pelo estabelecimento de ligações entre teoria e prática; pelo estabelecimento de ligações entre os distintos trabalhos de um segmento real de estudo. Tem por objeto as disciplinas escolares. Sua modalidade de ação implica a noção de ensino, de formação e tem como sistema de referência o sujeito aprendiz e sua relação com o conhecimento (LENOIR, 2008, p.52).
\end{abstract}

O caráter histórico-social é um dos fatores que caracterizam a educação interdisciplinar, pois vincula a teoria à prática, toma o aprendiz como responsável pela construção de seu conhecimento (subjetividade) tendo o professor como um mediador que o direciona por meio das possibilidades de escolha que este venha a tomar (dialogicidade).

Há quatro competências (FAZENDA, 2008) que podem estar presentes, em conjunto ou separadas, em um professor interdisciplinar: intuitiva (o professor busca sempre alternativas novas e diferenciadas para seu trabalho, é ousado), intelectiva (capacidade de reflexão tão forte que a transmite aos seus alunos), prática (organização espaço-temporal, usa técnicas diferenciadas), emocional (equilíbrio, autoconhecimento, tranquilidade e transmite segurança para o grupo).

O professor interdisciplinar possui elevado grau de comprometimento com a educação, com o seu trabalho, com o próximo, ama a pesquisa, o diálogo com os alunos e outros professores, busca desenvolver um projeto em parceria no qual reina o bem mútuo, apresenta humildade e afetividade, leva em consideração o saber instituído e o conhecimento de mundo dos seus alunos. É aquele no qual as pessoas sempre querem pedir-lhe opinião sobre algo. É aquele que enxerga, com um olhar erótico, o belo nas coisas mais simples.

A cultura apresenta um conceito amplo e envolve tudo o que diz respeito ao homem, o que ele retira da natureza, transforma e usa para seu proveito e suas práticas sociais cheias de símbolos e ritos de passagem. Cultura popular vai além de um sinônimo de folclore para transformar-se na "proposta de criação de uma cultura popular e identificar o trabalho político de conscientização e organização militante dos trabalhadores rurais e urbanos, a partir da crítica de uma cultura popular imposta e de intenção política de uma cultura popular libertadora a construir" (BRANDÃO, 1985, p.17, grifos do autor). Na cultura popular ocorre a valorização das tradições, danças, rezas, cantos, arte, gastronomia, lendas, vestuário, entre outros; é aquela na qual há um sentido de busca de liberdade, de reafirmação de valores, há um sentido de educação politizadora de formação de classes por intermédio de movimentos sociais de lutas e resistências.

O homem nasce, começa a engatinhar, balbucia, logo ensaia os primeiros passos e manifesta sua linguagem pelo uso de sons ou sinais gestuais. À medida que envelhece, o ser humano estabelece relações com seus semelhantes, cria símbolos, mitos, hábitos de vestir, frequenta a escola na qual aprende código linguístico culto do país em que vive. De um modo geral, tudo é cultura, tudo o que o ser humano utiliza da natureza, transforma e usa a seu favor. Para Brandão (1985):

De modo concreto, a cultura inclui objetos, instrumentos, técnicas e atividades humanas socializadas e padronizadas de produção de bens, da ordem social, de normas, palavras, ideias, valores, símbolos, preceitos, crenças e sentimentos. Destarte, ela abrange o universo do mundo criado pelo trabalho do homem sobre o mundo da natureza de que o homem é parte (BRANDÃO, 1985, p.20).

Na década de 1960, surgiram no Brasil diversas mobilizações em busca de uma Educação Popular na qual "a ideia de Cultura Popular e o horizonte de transformações profundas na ordem e na vida social no país são os polos de determinação da 
própria experiência". Tais mobilizações surgiram em oposição a uma cultura dominante com a "tarefa de retomar a cultura com o objetivo de motivá-la, através de um trabalho político de recriá-la com o povo, para conscientizá-lo através dele" (BRANDÃO, 1985, p.51; 30).

Durante o regime militar (1964-1985), houve um intenso processo de repúdio à repressão e à censura aplicados ao povo brasileiro. Apesar de toda essa violência, esse período teve uma grande atividade intelectual e artística, de modo velado, com uso das metáforas presentes nas letras de músicas e versos de poesias, contrastes de cores e seus matizes nas pinturas, modos de vestir das pessoas entre outros aspectos. Por meio da arte, buscava-se uma luz que viesse a clarear o período escuro e turbulento no qual o país enfrentava durante a ditadura com o despertar o povo para a conscientização política e a luta de classes. Um exemplo é a letra da música "O bêbado e a equilibrista", composta por Aldir Blanc e João Bosco (1979), com metáforas contra a ditadura: “Que sonha com a volta/Do irmão do Henfil/Com tanta gente que partiu/Num rabo de foguete/Chora! /A nossa Pátria/Mãe gentil/Choram Marias/e Clarisses/No solo do Brasil..."

A Arte e seu ensino são discutidos por Ana Mae Barbosa (2012), precursora e idealizadora da Abordagem Triangular para o ensino de Artes no Brasil, baseada na Discipline-Based Arts EducationDBAE. Segundo essa proposta, a construção do conhecimento em Artes ocorre quando a experimentação, a codificação e a informação se inter-relacionam. Para isso, o processo de ensino de arte deve abranger três ações básicas: a leitura de obras artísticas, a qual considera a pertinência, o esclarecimento e a abrangência, não se restringindo ao certo ou errado; o estímulo ao fazer artístico, não como cópia, mas, como interpretação, transformação e criação; a contextualização, relacionando a História da Arte com outras áreas do conhecimento (BARBOSA, 2012).

A história da educação no Brasil revela que sempre houve um embate político entre professores e os legisladores das políticas públicas educacionais para que a arte fizesse parte do currículo. Atualmente, a arte é considerada como cognição e as Diretrizes e Bases da Educação Nacional (Lei 9394/96) tornaram seu ensino obrigatório em todas as etapas da educação básica. Para Barbosa (2012, p. 19),

Por meio da Arte é possível desenvolver a percepção e a imaginação, apreender a realidade do meio ambiente, desenvolver a capacidade crítica, permitindo ao indivíduo analisar a realidade percebida e desenvolver a criatividade de maneira a mudar a realidade que foi analisada.

O ensino de Arte no Brasil passou por várias transformações que vão desde sua nomenclatura, concepções e espaço na grade curricular da educação básica. Para cada nomenclatura houve uma concepção diferente sobre a Arte e seu ensino. Educação Artística, Arte-Educação, Educação através da Arte, Arte e seu Ensino são alguns dos nomes usados no Brasil para tratar da inter-relação entre a Arte e seu ensino.

Frange (2012) explica-nos que a Educação Artística, termo instituído no Brasil pela Lei 5692/71, apresenta noção de laissez-faire, "partindo ora de uma sensibilização apenas primeira, ora simplistas apropriações de sucatas e/ou 'lixo limpo' para grotescas reproduções copistas (nada tendo a ver com criação e muito menos com processos inventivos)". Arte-Educação, como o hífen indica, aparece como tentativa de estabelecer as relações significativas entre Arte e Educação. Educação através da Arte foi um termo criado por Herbert Read em 1951. Arte e seu Ensino expressa as "propriedades estruturalmente constitutivas e constituintes das 'realidades', das práticas, dos discursos, dos objetos que interpretamos a serem compreendidos e ressignificados, ressemantizando pela Arte, seu ensino e sua compreensão em nossas vidas".

$\mathrm{O}$ arte-educador norte-americano Eisner (2013) comenta que os significados podem ser representados por meio de formas como palavras, números, imagens, movimento, proposições. Há uma linguagem específica a cada uma que expressa melhor o que as outras formas não conseguem. As imagens fotográficas, música, dança teatro e escultura são pertencentes ao domínio da arte. Sendo assim,

A gramática da arte é o meio pelo qual experimentamos os significados que as obras [dos artistas] possibilitam. As obras de arte falam o inefável, cultivam a sensibilidade, para que o sutil possa ser visto, o secreto desvelado. Em resumo, a arte nos ajuda a conhecer o que não podemos articular (EISNER, 2013, p.127).

A interdisciplinaridade, envolvendo o ensino da Arte e as demais disciplinas, precisa ser um aspecto bem pensado pelos professores, pois eles podem utilizar a linguagem artística para traduzir o que acontece na comunidade em que os alunos 
vivem, retratando fatos históricos, políticos, geográficos, entre outros. A Arte traduz o mundo fatídico em um mundo sensível, capaz de promover estesia, um fugere urbem para um lugar tranquilo, um sentimento que se torna conhecimento pelas sensações transmitidas em cores, formas, sons, palavras escritas (PARSONS, 2010).

\section{Metodologia}

A análise dos documentos legais foi norteada por Lüdke e André (2013, p.45), para quem "os documentos representam uma fonte natural de informação. Não são apenas uma fonte de informação contextualizada, mas surgem num determinado contexto". Como fontes primárias, eles foram trabalhados de acordo com o objetivo proposto, ou seja, buscou-se como as menções aos conceitos em estudo foram mencionadas no discurso da legislação.

Essa atividade foi realizada em quatro etapas: primeiramente, foi realizado o levantamento e a seleção dos documentos legais vigentes, referentes à Educação Básica no portal do Ministério da Educação; em seguida, realizou-se o estudo da literatura referente à interdisciplinaridade em obras de Fazenda (2001, 2008), do conceito de arte e de seu ensino em obras de Barbosa (2012), da cultura popular, em Brandão (1985) e da literatura referente às políticas educacionais em Dourado (2001); posteriormente, identificou-se quantitativamente a menção a cada descritor deste trabalho e, ao final, fez-se a análise qualitativa das menções identificadas.

A análise quantitativa ocorreu por meio da contagem de cada uma das palavras-chave em cada um dos documentos legais. Consideramos a ausência de menção também como informação importante.

\section{Análises documentais}

\section{Cultura popular}

Observou-se que na CF/88 (BRASIL, 1988) há apenas uma menção à cultura popular. $\mathrm{O}$ art. 215, em seu $\S 1^{\circ}$, determina que "o Estado protegerá as manifestações das culturas populares, indígenas e afro-brasileiras, e das de outros grupos participantes do processo civilizatório nacional". Essa proteção é contra quem ou o quê? A Lei Maior do país não nos explicita sobre isto.

A LDB (BRASIL, 1996) estabelece, em seu Art. $1^{\circ}$, que a educação abrange os "processos formativos que se desenvolvem na vida familiar, na convivência humana, no trabalho, nas instituições de ensino e pesquisa, nos movimentos sociais e organizações da sociedade civil e nas manifestações culturais", ou seja, uma educação que não ocorre somente nas instituições escolares. Isso reflete um ensino que propõe a integração do sujeito na cultura à qual ele pertence, de forma que ele possa interiorizá-la, pensar e rever seus valores. Não há menção à cultura popular, porém, no art. 26, caput, lê-se que há liberdade ofertada às instituições de ensino para que possam adequar seus currículos e planos pedagógicos conforme as características locais:

Art. 26. Os currículos da educação infantil, do ensino fundamental e do ensino médio devem ter base nacional comum, a ser complementada, em cada sistema de ensino e em cada estabelecimento escolar, por uma parte diversificada, exigida pelas características regionais e locais da sociedade, da cultura, da economia e dos educandos (BRASIL, 1996).

É nessa parte que os professores e a gestão escolar podem associar-se à sociedade em favor da valorização da cultura popular local.

Nas Diretrizes Curriculares Nacionais-DCN (BRASIL, 2013) há três menções à cultura popular contidas em seus pareceres homologados.

Conforme o Parecer CNE/CEB no 11/2010 para o Ensino Fundamental de nove anos:

Quando os conhecimentos escolares se nutrem de temas da vida social, também é preciso que as escolas se aproximem mais dos movimentos que os alimentam, das suas demandas e encaminhamentos. Ao lado disso, a interação na escola entre os conhecimentos de referência disciplinar e aqueles provenientes das culturas populares pode possibilitar o questionamento de valores subjacentes em cada um deles e a necessidade de revê-los, ao mesmo tempo em que permite deixar clara a lógica que preside cada uma dessas formas de conhecimento e que os torna diferentes uns dos outros, mas não menos importantes (BRASIL, 2013, p. 115-116).

Outra menção à cultura popular está no Parecer CNE/CEB n ${ }^{\circ}$ 11/2012 para a Educação Profissional Técnica de Nível Médio e revela que não se pode aceitar "um modelo de desenvolvimento econômico centrado na dilapidação da força de trabalho e das riquezas naturais, bem como [...] na promoção do individualismo e destruição dos valores essenciais das culturas populares (BRASIL, 2013e, 
p.209).

A terceira referência à cultura popular, contida apenas indica o art. 215 da $\mathrm{CF} / 88$ como um reforço ao seu art. 68 do Ato das Disposições Constitucionais Transitórias, que "reconhece os quilombos e garante direitos aos seus ocupantes: aos remanescentes das comunidades dos quilombos que estejam ocupando suas terras é reconhecida a propriedade definitiva, devendo o Estado emitir-lhes os títulos respectivos (BRASIL, 1988, grifo do relator)".

A liberdade e o apreço às manifestações das culturas populares estimados nas políticas educacionais demandam a atenção do governo para outros obstáculos que podem impedir sua concretização, como, por exemplo, melhoria na formação de professores, aperfeiçoamento e capacitação dos docentes e infraestrutura com equipamentos de áudio e vídeo disponíveis para transmissão de documentários. Além disso, Gomes (2011, p.226) afirma que "não há como limitar todas as expressões da diversidade e seus coletivos como "modalidades de ensino", mas a escola pode reajustar seu projeto político-pedagógico para que, por exemplo, as manifestações das culturas populares possam fazer parte tanto interdisciplinarmente, quanto dos projetos.

O PNE/14 (BRASIL, 2014), muito divulgado e discutido na mídia brasileira, não apresenta nenhuma referência à cultura popular. Podemos inferir uma tênue propensão dessa lei ao querer valorizar as culturas populares de cada comunidade, em seu art. $7^{\circ}$, parágrafo $4^{\circ}$, ao estabelecer que a União, os estados e os municípios deverão manter regime de colaboração entre si para o desenvolvimento de estratégias que levem em conta as "especificidades socioculturais e linguísticas de cada comunidade envolvida", por meio, de consultas prévias e informadas a cada comunidade. Por meio dessa afirmação, este documento legal deixa que cada instituição de educação básica escolha quais métodos serão utilizados para essas consultas e como serão transmitidos aos alunos os conhecimentos acerca de suas culturas populares.

Constatou-se em vários documentos legais (cf. art. 210 da CF/88, Art. 26 da Lei 9394/96, estratégia 7.20 da Lei 13005/14, Parecer CNE/CEB $n^{\circ}$ 20/2009, Parecer CNE/CEB no 5/2011, Parecer CNE/CEB $n^{\circ} 11 / 2012$, Parecer CNE/CEB $n^{\circ}$ 16/2012), que sempre há interesse pelo governo de que sejam abordadas as especificidades sociorregionais da arte, cultura, economia, entre outros. As escolas têm o dever, garantido legalmente, de que seus currículos, seus projetos temáticos, seus projetos político-pedagógicos, contenham, pesquisem e transmitam aos seus alunos, as culturas populares nas quais eles estão inseridos.

\section{Artes}

Foram identificadas diversas menções à palavra arte e seus cognatos: artística, artísticas, artísticos, artístico-culturais na $\mathrm{CF} / 88$ Constituição da República Federativa do Brasil (1988), totalizando cinco menções referentes à área educação.

Essa Carta Magna garante, por meio de seu art. 206, inciso II, assim como o art. $3^{\circ}$, inciso II, um ensino ministrado com base, entre outros, nos princípios da "liberdade de aprender, ensinar, pesquisar e divulgar o pensamento, a arte e o saber". Essa liberdade não deve ser confundida como um laissez-faire, o que seria uma fuga do propósito da Arte. $\mathrm{O}$ docente e as instituições escolares devem entender que Arte é uma disciplina que, como as outras, também tem conteúdos (BRASIL, 1988).

De acordo com o art. 208, inciso V, da $\mathrm{CF} / 88$, o Estado deverá promover o "acesso aos níveis mais elevados do ensino, da pesquisa e da criação artística, segundo a capacidade de cada um" (BRASIL, 1988, não paginado). Essa "capacidade de cada um" gera significados que podem ser interpretados de várias maneiras como, por exemplo, indicar capacidade intelectual ou limite financeiro das instituições de ensino.

$\mathrm{Na}$ Lei Maior (BRASIL, 1988, não paginado), observou-se, em seu art. 210, caput, que "serão fixados conteúdos mínimos para o ensino fundamental, de maneira a assegurar formação básica comum e o respeito aos valores culturais e artísticos, nacionais e regionais". Isso indica que os conteúdos relativos ao ensino de Arte devem difundir o respeito por cada expressão artística de cada cultura popular dos povos formadores de nosso país, bem como aos pertencentes a outros países.

Enquanto a $\mathrm{CF} / 88$ garantiu o conteúdo de Arte somente no ensino fundamental, a LDB/96 (BRASIL, 1996), em seu art. 26, parágrafo $2^{\circ}$, expandiu sua obrigatoriedade para os diversos níveis da educação básica, contemplando especialmente as suas expressões regionais, de forma a promover o desenvolvimento cultural dos alunos.

Por não explicitar o ensino de Arte em todas as etapas da Educação Básica, as instituições educacionais têm a possibilidade de oferecê-la apenas em uma das séries finais de cada uma das etapas. Uma eminente arte-educadora afirma que, no 
caso do ensino médio, algumas Secretarias de Educação usam a interdisciplinaridade para incluir todas as Artes na disciplina de Literatura, ficando tudo a cargo do professor de Língua e Literatura: Para ela, "essa é uma forma de eliminar as outras linguagens de Arte, fazendo prevalecer o espírito educacional hierárquico da importância suprema da linguagem verbal e consequente desprezo pela linguagem visual" (BARBOSA, 2012, p.13-14).

A Lei 9394/96 apresenta cinco menções à Arte. A partir dessa lei, no art. 26, parágrafo $2^{\circ}$, começa a ser usada a palavra Arte para designar o seu ensino na educação básica, apesar de vários de seus artigos ainda conterem o termo Educação Artística (BRASIL, 1996).

Constatou-se, ainda, que essa lei (BRASIL, 1996), art. 26-A, parágrafo, $2^{\circ}$, especifica que nas disciplinas Arte, História e Literatura e todo o currículo escolar há obrigação de conter referências à história e cultura afro-brasileira e dos povos indígenas.

O ensino de Música está previsto no art. 26 da LDB/96 (BRASIL, 1996), parágrafo $6^{\circ}$, como um dos componentes obrigatórios, mas não exclusivo, do currículo da educação básica. Observou-se que essa lei não explicitou em que eixo da Proposta Triangular seus conteúdos estarão alicerçados, se é no fazer, ler ou contextualizar. Alguns possíveis obstáculos encontram-se na escassez de profissionais formados em Música, além do número de aulas semanais, falta de recursos financeiros, má gestão, entre outros.

Para o ensino médio verificou-se, no art. 36, inc. I da LDB/96 (BRASIL, 1996), que são diretrizes norteadoras do currículo "a educação tecnológica básica, a compreensão do significado da ciência, das letras e das artes; o processo histórico de transformação da sociedade e da cultura; a língua portuguesa como instrumento de comunicação, acesso ao conhecimento e exercício da cidadania". Ao analisarmos o conteúdo desse artigo, percebemos que essa lei colocou arte junto com ciência e linguagem, através das vírgulas. Com isso, podemos perceber um interesse interdisciplinar no ensino de Arte para transmitir através da linguagem artística os conteúdos científicos de uma maneira didática e os vários códigos existentes na comunicação humana.

Localizaram-se 39 menções à Arte nas DCN/2013. No Parecer CNE/CEB n ${ }^{\circ} 11 / 2010$ (BRASIL, 2013d), que institui as Diretrizes Curriculares Nacionais para o Ensino Fundamental de 9 (nove) anos. Nele encontram-se outros conteúdos a serem ensinados nas aulas de Arte: a "Música constitui conteúdo obrigatório, mas não exclusivo, do componente curricular Arte, o qual compreende, também, as artes visuais, o teatro e a dança".

Quanto a quem deve exercer a docência de Arte nas séries iniciais da educação básica, o art. 31 da Resolução $n^{\circ}$ 07, de 14 de dezembro de 2010, que também fixa as DCN para o Ensino Fundamental de 9 (nove) anos, explicita que:

Do $1^{\circ}$ ao $5^{\circ}$ ano do Ensino Fundamental, os componentes curriculares Educação Física e Arte poderão estar a cargo do professor de referência da turma, aquele com o qual os alunos permanecem a maior parte do período escolar, ou de professores licenciados nos respectivos componentes (BRASIL, 2013c, p. 137).

No Plano Nacional de Educação de 2014 (BRASIL, 2014), há uma referência ao ensino de Artes, na estratégia 7.18 ao propor que as escolas públicas de educação básica deverão ter acesso aos bens culturais e artísticos. No entanto, essa lei peca ao não explicitar como deverá ser tal acesso, nem como deverão ser destinados os apoios financeiro e intelectual. A escola deverá levar os alunos aos museus, mostras de arte, eventos culturais ou os discentes continuarão a fazê-lo por meio de gravuras nos livros didáticos? Cabe aqui uma reflexão sobre esses conceitos para o próximo PNE 2014/2034. O aluno não deve ter acesso somente por livros didáticos, filmes, computador e televisor. Para que esse acesso exista é necessário que a instituição de ensino mantenha vínculo com museus, fundações culturais e artísticas, artistas de sua comunidade, acesso à internet entre outros. O professor deve, antes de tudo, organizar e classificar o que o aluno necessita saber antes de ir a esses lugares nos quais o acesso lhe é permitido, para que os objetivos do estudo sejam alcançados.

\section{Interdisciplinaridade}

Na década de 1980 havia, de acordo com Fazenda (2001), a necessidade de se analisar a viabilidade do desenvolvimento de um projeto interdisciplinar a partir da interdependência de outras variáveis que dependem da educação. Inúmeras dicotomias necessitavam ser enfrentadas pelos pesquisadores como teoria/prática, verdade/erro, certeza/dúvida, processo/produto, real/simbólico, ciência/arte; o que fez essa década ser marcada, nos estudos sobre a interdisciplinaridade, pela necessidade de se explicitar os equívocos surgidos a partir delas. Um dos pesquisadores pioneiros no Brasil afirma que: 
Uma visita às decisões dos poderes Legislativo e Executivo esclareceu-me sobre o quadro de "conveniências", no qual a educação para a interdisciplinaridade foi gestada. Analisei como foram gradativamente caladas as vozes dos educadores, dos alunos e o processo de entorpecimento pelo qual passaram as consciências esclarecidas, analisei também a mudez da imprensa e o conluio desonesto na articulação das propostas educacionais (FAZENDA, 2001, p.30, grifo da autora).

Não foi identificada menção à interdisciplinaridade na CF/88 (BRASIL, 1988). Tal como foi afirmado pela pesquisadora (FAZENDA, 2001), o país passava por um período turbulento no qual havia necessidade de o país se reestruturar financeiro e tecnologicamente. Como o Brasil precisava de mão de obra barata, eficiente e em tempo hábil para pagar os empréstimos que lhe foram concedidos por bancos internacionais, criaram-se muitos cursos técnicos, nos quais não se priorizava uma educação integradora, na qual o ser humano fosse respeitado em suas peculiaridades e na vida coletiva.

A LDB/96 (BRASIL, 1996), por sua vez, igualmente não apresenta menção à interdisciplinaridade. Coadunando com essa ausência, encontrou-se uma tendência ainda pluri e multidisciplinar, em seu art. 52, definindo as universidades como "instituições pluridisciplinares de formação dos quadros profissionais de nível superior, de pesquisa, de extensão e de domínio e cultivo do saber humano". Para que a interdisciplinaridade seja base para um currículo na educação básica é necessário, então, que as instituições de ensino superior formadoras de professores também o tenham. Houve então uma revisão desses conceitos nas políticas educacionais e as diretrizes curriculares vieram para sanar ou, pelo menos, tentar sanar a falta ou os equívocos na interpretação. Nas DCN a interdisciplinaridade aparece em 99 menções.

Entende-se a interdisciplinaridade, por meio do Parecer CNE/CEB $n^{\circ} 7 / 2010$, como a transferência de métodos de uma disciplina para outra, por meio de diálogo no qual cada disciplina mantém suas características, e deve ocorrer por temas transversais ou projetos temáticos, ou seja,

A interdisciplinaridade pressupõe a transferência de métodos de uma disciplina para outra. Ultrapassa-as, mas sua finalidade inscreve-se no estudo disciplinar. Pela abordagem interdisciplinar ocorre a transversalidade do conhecimento constitutivo de diferentes disciplinas, por meio da ação didáticopedagógica mediada pela pedagogia dos projetos temáticos. A interdisciplinaridade é, portanto, entendida aqui como abordagem teóricometodológica em que a ênfase incide sobre o trabalho de integração das diferentes áreas do conhecimento [...] (BRASIL, 2013a, p.28).

Na Resolução n 04/2010 (BRASIL, 2013b), em seu art. 17, constatou-se que a matriz curricular da Educação básica deve destinar, pelo menos, 20\% do total da carga horária anual ao conjunto de programas e projetos interdisciplinares eletivos criados pela escola. Se $80 \%$ do currículo não necessita ser interdisciplinar, como deverá existir a unidade do saber, a valorização do sujeito no ensino, o diálogo entre as demais disciplinas, tanto por meio da transferência de métodos com por meio da ligação entre as ciências? Essa porcentagem é um valor ínfimo ao considerar-se as várias dicotomias que necessitam ser superadas.

No PNE/14 há duas menções à interdisciplinaridade, mas apenas uma delas corresponde ao ensino na modalidade educação básica. A Lei 13005/14 (BRASIL, 2014), em sua estratégia 3.1 de sua Meta 3, refere-se ao currículo voltado para temas transversais e projetos temáticos. Com o objetivo de elevar a universalização do ensino médio com o correspondente aumento de sua taxa líquida de matrículas para $85 \%$ (oitenta e cinco por cento) surgiu a necessidade de incentivar práticas

estruturadas pela relação entre teoria e prática, por meio de currículos escolares que organizem, de maneira flexível e diversificada, conteúdos obrigatórios e eletivos articulados em dimensões como ciência, trabalho, linguagens, tecnologia, cultura e esporte, garantindo-se a aquisição de equipamentos e laboratórios, a produção de material didático específico, a formação continuada de professores e a articulação com instituições acadêmicas, esportivas e culturais (BRASIL, 2014, não paginado).

Assim, procurava-se institucionalizar um programa nacional de renovação do ensino médio por meio de abordagens interdisciplinares.

É possível afirmar, com Dourado e Oliveira (2009, p. 206), que se torna necessária, em relação à educação como um todo,

a priorização da educação como política pública, a ser efetivamente assegurada, o que implica: aumento dos recursos destinados à educação, 
regulamentação do regime de colaboração entre os entes federados, otimização e maior articulação entre as políticas e os diversos programas de ações na área; efetivação da gestão democrática dos sistemas e das escolas, consolidação de programas de formação inicial e continuada, articulados com a melhoria dos planos de carreira dos profissionais da educação.

Dimensões que não podem esquecer a concepção de homem e de sociedade que se deseja construir.

\section{Palavras finais}

Sintetizando, pode afirmar-se que a Lei de Diretrizes e Bases da Educação Nacional-LDB/96 do mesmo modo não mencionou interdisciplinaridade. No entanto, as DCN mencionaram 99 vezes. Nelas, constatou-se como os legisladores e educadores expressaram sua concepção de educação: projetos temáticos e transferência de métodos de uma disciplina para outra. De uma maneira tímida novamente, o Plano Nacional de Educação-PNE/14 mencionou o ensino interdisciplinar duas vezes.

Enquanto que na $\mathrm{CF} / 88$ houve uma referência à cultura popular, a voz calou-se na LDB/96. Foi tomada novamente na DCN com três menções e calada, mais uma vez, no PNE/14. Na $\mathrm{CF} / 88$ e LDB/96, a Arte foi mencionada cinco vezes em cada uma. As DCN/2013 referiram-se a ela 39 vezes e o PNE/14 apenas uma vez.

Esses dados quantitativos expressam, como refletido em linhas anteriores, que as questões relacionadas à arte, à cultura popular e à interdisciplinaridade ainda são timidamente discutidas e propostas. Nos documentos legais analisados, pode-se perceber que, com o passar dos anos, existiram muitos confrontos e embates políticos e educacionais que fizeram com que uns sobressaíssem mais do que outros.

Aprendeu-se, neste estudo, que o ensino de Arte passou por várias nomenclaturas nas quais seus conceitos foram distintos em cada uma delas. O ensino de Arte, antes tido como objeto de recreação e passatempo dos alunos, passou a ser visto pelos educadores e legisladores como uma disciplina com conteúdos que devem ser respeitados, sem os quais o propósito da Arte, que tem um fim em si mesma, deixa de existir. A Arte deve trazer a essência do maravilhoso que há no mundo, traduzir coisas que outras linguagens não dizem e dizer coisas que as outras não podem.

Além disso, há obstáculos diretos que interferem na concretização dos documentos legais como, por exemplo, formação dos professores em cursos de licenciatura mal qualificados; custos elevados de cursos de pós-graduação lato e stricto sensu e baixos salários docentes; infraestrutura inadequada das escolas nas quais a maioria não possui sala de arte, má gestão institucional, materiais pedagógicos inexistentes ou de baixa qualidade, mau comportamento dos alunos.

Há também empecilhos indiretos como a falta de acompanhamento escolar por pais que delegam toda a responsabilidade da educação aos professores, falta de diálogo ou parceria com demais docentes, entre outros.

É necessário que o educador tenha empatia pelo seu trabalho, espírito solidário e abertura ao diálogo. As políticas educacionais foram e continuam dependendo de muitos embates para que os anseios do campo educacional e de toda a sociedade sejam realizados.

\section{Nota}

\section{Apoio CAPES-OBEDUC/ FAPEMIG/CNPq.}

\section{Referências}

BARBOSA, A. M.. As mutações do conceito e da prática. In: ___ (Org.). Inquietações e mudanças no ensino da arte. 7 ed. São Paulo: Cortez, 2012, p.13-27.

BLANC, Aldir; BOSCO, João. $O$ bêbado $e$ a equilibrista. Disponível em: <http://musicasdahistoria.blogspot.com.br/2010/03/f ascinante-o-bebado-e-equilibrista-de.html>. Acesso em 20 abr. 2015.

BRANDÃO, Carlos Rodrigues. A educação como cultura. São Paulo: Brasiliense, 1985.

BRASIL. Constituição da República Federativa do Brasil de 1988, promulgada em 05 de outubro de 1988. Brasília, DF: Senado Federal, 1988. Disponível em: <http://www.planalto.gov.br/ccivil_03/constituicao/ constituicao.htm>. Acesso em 20 maio. 2015. Não paginado.

Lei Federal $n^{o}$ 9394/96, de 20 de dezembro 
de 1996. Estabelece as Diretrizes e Bases da Educação Nacional. Diário Oficial da União, Ano CXXXIV, n. 248, 23 de dezembro de 1996, p. 27833 27841. Brasília, 1996. Disponível em: < www.planalto.gov.br/ccivil_03/leis/19394.htm>. Acesso em 30 jul. 2014. Não paginado.

Câmara de Educação Básica. Conselho Nacional de Educação. Resolução n. CNE/CEB 04/2010, de 13 de julho de 2010. Define as Diretrizes Curriculares Nacionais Gerais para a Educação Básica. Brasília/DF: MEC, SEB, DICEI, 2013b. Disponível em: http://portal.mec.gov.br/index.ph p?option=com_content $\&$ id=12992:diretrizes-para-aeducacao-basica Acesso em 12 maio 2015.

Câmara de Educação Básica. Conselho Nacional de Educação. Parecer n. CNE/CEB 07/2010, de 07 de abril de 2010. Fixa as Diretrizes Curriculares Nacionais Gerais para a Educação Básica. Brasília/DF: MEC, SEB, DICEI, 2013a. Disponível em: http://portal.mec.gov.br/index.ph p?option=com_content\&id=12992:diretrizes-para-aeducacao-basica Acesso em 12 maio 2015.

Câmara de Educação Básica. Conselho Nacional de Educação. Resolução n. CNE/CEB 07/2010, de 14 de dezembro de 2010. Fixa as Diretrizes Curriculares Nacionais para o Ensino Fundamental de 9 (nove) anos. Brasília/DF: MEC, SEB, DICEI, 2013c. Disponível em: http://portal.mec.gov.br/index.php?option=com_con tent\&id=12992: diretrizes-para-a-educacao-basica. Acesso em 12 fev. 2014.

Câmara de Educação Básica. Conselho Nacional de Educação. Parecer n. CNE/CEB 11/2010, de 07 de julho de 2010. Aprova as Diretrizes Curriculares Nacionais para o Ensino Fundamental de 9 (nove) anos. Brasília/DF: MEC, SEB, DICEI, 2013d. Disponível em: http://portal.mec.gov.br/index.php?option=com_con tent\&id=12992: diretrizes-para-a-educacao-basica. Acesso em 12 fev. 2014.

Câmara de Educação Básica. Conselho Nacional de Educação. Parecer n. CNE/CEB 11/2012, de 09 de maio de 2012. Aprova as Diretrizes Curriculares Nacionais para a Educação Profissional Técnica de Nível Médio. Brasília/DF: MEC, SEB, DICEI, 2013e. Disponível em: http://portal.mec.gov.br/index.php?option=com_con tent\&id=12992:diretrizes-para-a-educacao-basica.
Acesso em 12 fev. 2014.

. Ministério da Educação. Plano Nacional de Educação - Lei 13005/14, de 25 de junho de 2014. Brasília, DF: INEP, 2001. Disponível em: <http://www2.camara.leg.br/legin/fed/lei/2014/lei13005-25-junho-2014-778970-publicacaooriginal144468-pl.html>. Acesso em 23 abr. 2015.

DOURADO, L. F.. A reforma do Estado e as políticas de formação de professores nos anos 1990. In: _ _ PARO, Vítor Henrique. (Orgs.). Políticas públicas e educação básica. São Paulo: Xamã, 2001, p.49-57.

DOURADO, L.F.; OLIVEIRA, J. F.. A qualidade da educação: perspectivas e desafios. Cad. Cedes, Campinas, v. 29, n. 78, p. 201-215, maio/ago. 2009.

EISNER, E.. Estrutura e mágica no ensino da Arte. In: BARBOSA, Ana Mae (Org.). Arte-Educação: leitura no subsolo. 9 ed. São Paulo: Cortez, 2013, p.111-129.

FAZENDA, I. C. A.. Interdisciplinaridade: história, teoria e pesquisa. 8 ed. Campinas, SP: Papirus, 2001.

$O$ que é interdisciplinaridade. São Paulo: Cortez, 2008.

FRANGE, L. B. P. Arte e seu ensino, uma questão ou várias questões? In: BARBOSA, Ana Mae (Org.). Inquietações e mudanças no ensino da Arte. 7. ed. São Paulo: Cortez, 2012, p.37-51.

GOMES, N. L. O Plano Nacional de Educação e a diversidade: dilemas, desafios e perspectivas. In: DOURADO, Luiz Fernandes (Org.). Plano Nacional de Educação (2011-2020): avaliação e perspectivas. 2 ed. Goiânia: Editora UFG; Belo Horizonte: Autêntica Editora, 2011. p.219-261.

LENOIR, Y.. Didática e interdisciplinaridade: uma complementaridade necessária e incontornável. In: FAZENDA, I. (org.). Didática $e$ interdisciplinaridade. 13 ed. Campinas, SP: Papirus, 2008, p.45-75.

LÜDKE, M.; ANDRÉ, M. E.D. Afonso de. Pesquisa em educação: abordagens qualitativas. 2 ed. Rio de Janeiro: E.P.U., 2013.

PARSONS, M. Currículo, arte e cognição integrados. Trad. de Leda Guimarães. In: 
BARBOSA, A. M. (Org.). Arte/Educação São Paulo: Cortez, 2010, p.295-317. contemporânea: consonâncias internacionais. 3 ed.

\section{Sobre os autores}

Leonardo Marcelino: Licenciado em Letras pela Universidade de Uberaba. Professor de Língua Inglesa e Língua Portuguesa pela Secretaria de Educação do Estado de Minas Gerais. Ex-bolsista de Iniciação Científica do Observatório da Educação Interdisciplinaridade na Educação Básica: estudos por meio da Arte e da cultura popular.

Sueli Teresinha de Abreu-Bernardes: Doutora em Educação pela UFG; pesquisadora no PPGE-UNIUBE, coordenadora institucional do Observatório da Educação Interdisciplinaridade na Educação Básica: estudos por meio da Arte e da cultura popular; membro da Sociedade de Estudos e Pesquisas Qualitativos; do Círculo Latinoamericano de Fenomenología; da Association Internationale Gaston Bachelard e da Rede de Pesquisadores sobre o Professor do Centro-Oeste.

Recebido em setembro de 2015.

Aprovado em maio de 2016. 